\title{
APROPRIAÇÃO E EXPLORAÇÃO ENQUANTO FACES DA NOVA COLONIALIDADE LATINO-AMERICANA: LIMITES E POSSIBILIDADES PARA A CONSTRUÇÃO DE UM REGIME SUI GENERIS.
}

\author{
OWNERSHIP AND EXPLOITATION OF THE NEW FACES AS COLONIALITY \\ LATIN AMERICAN: LIMITS AND POSSIBILITIES FOR THE CONSTRUCTION \\ OF A SUI GENERIS REGIME.
}

\author{
Evilhane Jum Martins ${ }^{1}$ \\ Jerônimo Siqueira Tybusch ${ }^{2}$
}

\section{RESUMO}

A pesquisa objetiva analisar os paradigmas que atrelam a América Latina ao processo de colonialidade relativamente à apropriação da sociobiodiversidade, com possíveis soluções desde um regime sui generis. Assim, quais os limites e possibilidades para a construção de um regime sui generis que subverta a ordem posta? Para responder, optou-se pela perspectiva sistêmica através da pesquisa bibliográfica e documental. Como resultado, o regime sui generis apresenta-se como meio capaz de subverter a ordem posta enquanto instrumento regional que equilibre interesses na esfera pública, notadamente nos sistemas da economia, política, direito, ecologia e cultura.

Palavras-chave: Nova Colonialidade, Patrimônio Genético, Conhecimentos Tradicionais, Regime Sui Generis, América Latina.

\begin{abstract}
The research aims to analyze the paradigms which link Latin America to Coloniality procedure for the appropriation of sociobiodiversity with possible solutions from a sui generis regime. Thus, the limits and possibilities for the construction of a sui generis regime which subverts the order placed? To answer, we opted for the systemic perspective through bibliographical and documentary research. As a result, the sui generis regime is presented as a means capable of subverting the order placed as a regional instrument that balances interests in the public sphere, particularly in the systems of economy, politics, law, ecology and culture.
\end{abstract}

Keywords: New Coloniality, Genetic Resources, Traditional Knowledge, Sui Generis Regime, Latin America.

\footnotetext{
${ }^{1}$ Mestranda em Direito pela Universidade Federal de Santa Maria - UFSM, Rio Grande do Sul, (Brasil). Linha de Pesquisa: Direitos da Sociobiodiversidade e Sustentabilidade. E-mail: evilhane martins@ hotmail.com

${ }^{2}$ Doutor em Ciências Humanas pela Universidade Federal de Santa Catarina - UFSC, Florianópolis, (Brasil). Professor Adjunto I da Universidade Federal de Santa Maria - UFSM. E-mail: jeronimotybusch@ufsm.br
} 


\section{INTRODUÇÃO}

A América Latina apresenta-se no cenário internacional como sujeito subordinado a questões de cunho socioeconômico, impostas pelo mundo capitalista. Em contrapartida, seu território é berço de inúmeras riquezas naturais e imensurável diversidade de espécies de organismos vivos. Entretanto, historicamente o continente latino-americano é alvo do caráter lucrativo que o capitalismo global impõe à biodiversidade existente no continente e os conhecimentos atrelados à sua utilização.

Todavia, a problemática surge quando se observa os parâmetros consistentes na dominação do continente através da exploração do patrimônio genético e dos conhecimento tradicionais revela-se como pressuposto de um processo de colonialidade.

Nesse sentido, a presente pesquisa objetiva analisar os reais paradigmas que atrelam a América Latina aos parâmetros dessa colonialidade - levando em conta tão somente a exploração do patrimônio genético e dos conhecimento tradicionais -, assim como possíveis soluções aventadas a partir da construção de um regime sui generis.

Por consequência, busca-se responder a seguinte problemática: Quais os limites e possibilidades para a construção de um regime sui generis capaz de subverter a ordem posta, no que diz respeito a exploração desordenada do patrimônio genético e dos conhecimentos tradicionais, decorrentes dos parâmetros da nova colonialidade latino-americana?

Para responder a este questionamento, a metodologia empregada obedece ao trinômio: Teoria de Base/Abordagem, Procedimento e Técnica. Como Teoria de Base e Abordagem optou-se pela perspectiva sistêmica, utilizando-se autores com visão multidisciplinar e conectando ares do saber como ecologia, ciência política, sociologia e direito. Os procedimentos elegidos foram a pesquisa bibliográfica e documental (em meios físicos e digitais - sites e redes sociais). A técnica empregada foi a construção de fichamentos e resumos estendidos.

\section{1 - PATRIMÔNIO GENÉTICO E CONHECIMENTOS TRADICIONAIS: SUBSÍDIOS PARA O PROCESSO DE COLONIALIDADE LATINO-AMERICANA.}

As decorrências contemporâneas do sistema posto à América Latina e o caráter desenvolvimentista impregnado em ações impostas de modo vertical - centro-periferia garantem o destoamento da realidade vivenciada com o discurso hegemônico, de modo a 
aprofundar incessantemente o abismo existente entre desenvolvimento e subdesenvolvimento.

O pensamento dominante, capaz de adentrar no território latino-americano por meio de construções discursivas hegemônicas que visam o florescimento dos desejos desenvolvimentistas, geram então pressupostos para o sucesso do processo de colonialidade ${ }^{3}$, através da imposição do sistema capitalista e suas regras como única forma de se obter o dito desenvolvimento. A questão que surge, no entanto, é justamente a consistência do conceito de desenvolvimento no momento em que se leva em conta o lugar e o tempo em que se está.

Nesse contexto, a historicidade latino-americana revela claramente o caráter periférico atribuído ao continente desde sua colonização, fomentado continuadamente ao longo dos séculos de modo a privilegiar a sua submissão à países desenvolvidos que acabam por ditar questões cruciais para a definição do rumo a ser seguido pela América Latina em todas as searas ${ }^{4}$. Diante desse quadro, restam prejudicadas todas as formas de reconhecimento próprio de cultura e identidade latino-americanas em virtude da submissão que atrela a América Latina a ditames pós-coloniais reveladores do processo de colonialidade.

Portanto, enquanto território subserviente, mas indispensável ao sistema capitalista, a América Latina consiste em região periférica do globo a qual os ditames do Norte Social ${ }^{5}$ soam

\footnotetext{
${ }^{3}$ Para elucidar os desdobramentos sociopolíticos desse processo, Quijano (1997) cunhou o conceito de colonialidade como algo que transcende as particularidades do colonialismo histórico e que não desaparece com a independência ou descolonização. Essa formula- ção é uma tentativa de explicar a modernidade como um processo intrinsecamente vinculado à experiência colonial. Essa distinção entre colonialidade e colonialismo permite, portanto, explicar a continuidade das formas coloniais de dominação, mesmo após o fim das administrações coloniais, além de demonstrar que essas estruturas de poder e subordinação passaram a ser reproduzidas pelos mecanismos do sistema-mundo capitalista colonial-moderno. Dessa maneira, a noção de colonialidade atrela o processo de colonização das Américas à constituição da economia-mundo capitalista, concebendo ambos como partes integrantes de um mesmo processo histórico iniciado no século XVI (Castro-Gomez; Gosfroguel, 2007) (ASSIS, Wendell Ficher Teixeira. Do colonialismo à colonialidade: expropriação territorial na periferia do capitalismo. In: Caderno CRH, v. 27, n. 72. Salvador: set-dez. 2014. Disponível em: http://www.scielo.br/pdf/ccrh/v27n72/11.pdf -Acesso em 15 de setembro de 2016, p. 614).

${ }^{4}$ A América constitui-se como o primeiro espaçotempo de um padrão de poder de vocação mundial e, desse modo e por isso, como a primeira id-entidade da modernidade. Dois processos históricos convergiram e se associaram na produção do referido espaçotempo e estabeleceram-se como os dois eixos fundamentais do novo padrão de poder. Por um lado, a codificação das diferenças entre conquistadores e conquistados na ideia de raça, ou seja, uma supostamente distinta estrutura biológica que situava a uns em situação natural de inferioridade em relação a outros. Essa ideia foi assumida pelos conquistadores como o principal elemento constitutivo, fundacional, das relações de dominação que a conquista exigia. Nessas bases, consequentemente, foi classificada a população da América, e mais tarde do mundo, nesse novo padrão de poder. Por outro lado, a articulação de todas as formas históricas de controle do trabalho, de seus recursos e de seus produtos, em torno do capital e do mercado mundial (QUIJANO, Aníbal. Colonialidade do poder, eurocentrismo e América Latina. Consejo Latinoamericano de Ciencias Sociales. Buenos Aires, CLACSO 2005, p. 117).

${ }^{5}$ Ao discorrer acerca das Epistemologias do Sul, Santos demonstra a diferença crucial entre o Norte e o Sul: definidos assim de acordo com a perspectiva social, não levando em conta tão somente os aspectos geográficos: Desde mi punto de vista, las Epistemología del Sur son el reclamo de nuevos procesos de producción, de valorización de conocimientos válidos, científicos y no científicos, y de nuevas relaciones entre diferentes tipos de conocimiento, a partir de las prácticas de las clases y grupos sociales que han sufrido, de manera sistemática, destrucción, opresión y discriminación causadas por el capitalismo, el colonialismo y todas las naturalizaciones de
} 
como comandos do modo de vida a serem transcritos para a realidade latino-americana. Disso decorre a construção de pensamentos latinos que rejeitam a historicidade e a identidade do continente, em prol da importação de elementos históricos e identitários que não lhe são próprios, mas que são tidos universalmente como corretos e aceitáveis.

Nesse diapasão, a emergência dos novos tempos coloca em xeque a questão da exploração da biodiversidade existente no continente latino-americano nos parâmetros da colonialidade, levando em conta as riquezas e características próprias da América Latina, que acabam por atrair a atenção global face as necessidades e fragilidades mundiais em decorrência das ações humanas de degradação generalizada dos recursos naturais necessários para manutenção da vida humana.

\begin{abstract}
En América del Sur se encuentra también el pulmón verde del planeta, la región de mayor biodiversidad y riqueza genética del mundo: la Amazonia, uma región codiciada por EE.UU y otros países. La Amazonia compone um inmenso conjunto de territorios selváticos sobre los cuales discurren más de mil ríos y que contituyen la mayor cuenca hidrográfica del mundo. Cerca del $70 \%$ de su espacio físico está cubierto por bosques tropicales húmedos que en su conjunto semejan un oceano verde. Su superfície es de unos 8.000.000 de kilómetros cuadrados y es compartida por Brasil (donde representa el 56\% de la superfície total del país), Venezuela, Colombia, Perú, Bolivia, Ecuador, Guyana, Surinam y Guayana Francesa.

La región posee un quinto del água Dulce del planeta; el mayor banco genético del mundo en biodiversidad (un kilómetro cuadrado de la Amazonia contiene mayor número de especies vegetales que los territórios de Canadá y EE.UU juntos); un tercio de las florestas y de las reservas mundiales de los bosques; grandes recursos ictícolas con sus ríos, lagos y lagunas; una riquísima fauna terrestre; yacimientos de oro, hierro, bauxita, estaño, cobre, zinc, manganeso; el 95\% de las reservas de nióbio del mundo que se encuentran en el alto Río Negro y que se utiliza en los aceros de las naves espaciales y de los misiles intercontinentales; el 96\% de las reservas de titânio, tungsteno, también utilizados en la industria aeronáutica-espacial y militar; petróleo, gas y muchos otros recursos ${ }^{6}$.
\end{abstract}

la desigualdad en las que se han desdoblado; el valor de cambio, la propiedad individual de la tierra, el sacrificio de la madre tierra, el racismo, al sexismo, el individualismo, lo material por encima de lo espiritual y todos los demás monocultivos de la mente y de la sociedad -económicos, políticos y culturales- que intentan bloquear la imaginación emancipadora y sacrificar las alternativas. En este sentido, son un conjunto de epistemologías, no una sola, que parte de esta premisa, y de un Sur que no es geográfico, sino metafórico: el Sur antiimperial. Es la metáfora del sufrimiento sistemático producido por el capitalismo y el colonialismo, así como por otras formas que se han apoyado en ellos como, por ejemplo, el patriarcado. Es también el Sur que existe en el Norte, lo que antes llamábamos el tercer mundo interior o cuarto mundo: los grupos oprimidos, marginados, de Europa y Norteamérica. También existe un Norte global en el Sur; son las elites locales que se benefician del capitalismo global. Por eso hablamos de un Sur antiimperial. Es importante que observemos la perspectiva de las Epistemologías del Sur desde este punto de partida (Santos, Boaventura de Sousa., Introducción: las epistemologías del Sur in CIDOB (org.), Formas-Otras. Saber, nombrar, narrar, hacer. Barcelona: CIDOB Ediciones, 2011, p. 16)

${ }^{6}$ BRUZZONE, Elsa. Las guerras del água: América del Sur, en la mira de las grandes potencias. $1^{\text {a }}$ Ed. Buenos Aires: Capital Intelectual, 2009, p. 101-102. 
Por consequência, tais características sugerem um novo modelo de dominação inserto no processo de colonialidade, em que a apropriação dos recursos genéticos e a mercadorização da biodiversidade é o ponto crucial. Assim, a realidade da América Latina, enquanto berço da biodiversidade em âmbito mundial, passa a refletir traços do capitalismo cuja imposição se perpetua no cenário contemporâneo por elementos próprios do processo de colonialidade: aquela correspondente à mercadorização da biodiversidade ${ }^{7}$ e todas as informações pertinentes a identidade geográfica, ambiental e genética do continente.

Nesse cenário, os países latino-americanos figuram tão somente como meros fornecedores de recursos que irão fomentar a biotecnologia: condição eternizada em decorrência da fragilidade do continente no que tange a projeções meramente econômicas.

$\mathrm{Na}$ seara internacional, havendo como marco regulatório do acesso à recursos genéticos a Convenção sobre Diversidade Biológica: único instrumento normativo internacional que confere tratamento amplo à biodiversidade, com o objetivo maior de alcançar o equilíbrio entre conservação e utilização dos recursos naturais; tem-se que os objetivos precípuos da acabam por ser nulificados pela subversão da norma, ou ainda pela sobreposição do Acordo Trips.

Há que se lembrar que os maiores entraves pertinentes aos conhecimentos tradicionais e sua interrelação com a propriedade intelectual são causados pelo confronto existente entre Acordo Trips (OMC) e Convenção sobre Diversidade Biológica. Neste sentido, importante referir a lição de Vinícius Garcia Vieira:

\begin{abstract}
As contradições entre os interesses do comércio internacional de biotecnologias e as necessidades de proteção da biodiversidade são produzidas, e simultaneamente produzem interações entre os objetivos colocados na $\mathrm{CDB}$ e a finalidade de apropriação individual das produções do intelecto para o comércio, constantes no Trips. No tabuleiro das relações internacionais, caminhos opostos resultam do entrechoque entre o regime de proteção da biodiversidade, em formação, e o regime de propriedade intelectual, em plena força e vigor.

No cenário internacional observa-se que os países latino-americanos, inseridos na posição de países do Sul, têm postulado a abertura do regime de propriedade intelectual, sob o modelo Trips, aos objetivos da CDB de conservar a biodiversidade mediante sua utilização dos recursos genéticos e transferir tecnologia, de forma a seguir o caminho de cuidado da biodiversidade, com a construção de espaço para valorização cultural dos conhecimentos dos povos indígenas e comunidades tradicionais $^{8}$.
\end{abstract}

\footnotetext{
${ }^{7}$ VIEIRA, Vinicius Garcia. Direito da biodiversidade e América Latina: a questão da propriedade intelectual. Ijuí: Unijuí, 2012, p. 105.

${ }^{8}$ Idem, p. 121.
} 
Situando tais paradigmas ao cenário latino-americano pode-se dizer que a queda do Muro de Berlim pode ser identificada como ponto de partida para a subsunção da América Latina à nova concepção de colonialidade, já citada: consistente na dominação econômica, social e cultural do continente latino-americano pelos países do norte.

O clima de conformismo decorrente do fim da guerra fria, cria as condições necessárias para que a América Latina passe a aceitar as imposições supervenientes da vitória do capitalismo no momento histórico que se vivia. Nesse clima de estabilidade mundial imposta, o Consenso de Washington(1989) surge como propostas modernizadoras que visam a realização de uma reforma neoliberal nos países latino-americanos, visando instituir a consolidação estrutural da América Latina, seguindo o modelo norte-americano.

A questão é que esse emaranhado geopolítico faz com que o patrimônio genético e os conhecimentos tradicionais associados sejam elementos desprezados pela própria América Latina, que se submete à exploração desenfreada e ao saque de informações preciosas para venerar a tecnização e a cientifização de recursos que lhe são originários, em uma cadeia que reproduz o saber hegemônico sem reconhecer formas próprias de saber. Com isso, a passividade da América Latina no sofisticado processo de subserviência e exploração desordenada, consiste no elemento principal que sustenta a apropriação da informação do patrimônio genético e dos conhecimentos tradicionais associados.

Assim, o processo de colonialidade provém do modo de ascensão do capitalismo após a Segunda Guerra Mundial, modo este que consiste sumariamente na substituição dos padrões até então estabelecidos nos relacionamentos interestatais - os quais passam a emoldurar o capitalismo como o único regime capaz de garantir o modelo socioeconômico tido como desenvolvido, tendo como fundamento as conquistas de nações hegemônicas, cujas ações devem ser observadas como referências a serem seguidas por países com características socioeconômicas diferenciadas: o que os torna subdesenvolvidos ${ }^{9}$.

\footnotetext{
${ }^{9}$ Acerca do assunto, Pedro de Araujo Quental assevera que: Escobar (1996) busca compreender o desenvolvimento como um discurso produzido historicamente. O desenvolvimento, assim como o conceito de Terceiro Mundo, é compreendido pelo autor como uma representação social formulada no período Pós-Segunda Guerra Mundial, justificando, então, a aplicação de programas e políticas econômicas em países ditos "subdesenvolvidos". Quando pensamos que "temos que nos desenvolver", afirma Escobar (1996), este fato constata a vigência de uma ideia de desenvolvimento naturalizada nos nossos modos de sonhar, pensar e de ser. Isto ocorre na medida em que regiões do mundo como África, Ásia e América Latina foram inventadas a partir de um profundo processo simbólico e material como sendo subdesenvolvidas: fomos "inventados como subdesenvolvidos", afirma o autor (Escobar, 2009:26). Nesse sentido, para Escobar a ideia de "desenvolvimento" deve ser vista como uma invenção geopolítica que tem por objetivo localizar indivíduos, grupos e territórios como "não-desenvolvidos" ou "subdesenvolvidos", legitimando, assim, ações de suposto combate a essa condição (QUENTAL, Pedro de Araujo. Dilemas da integração regional na América do Sul: a lógica territorial da IIRSA e suas implicações socioespaciais. Conselho Latino-americano de Ciências Sociais.
} 
Além da sedimentação dessa divisão entre países desenvolvidos e subdesenvolvidos, o empoderamento e autonomia das corporações com a minimização do papel do Estado na economia internacional, bem como a criação de organismos não-estatais na esfera transnacional, atua como forma de legitimar ações em prol da geração do capital através de facilidades atinentes à produção e circulação: surge aí o imperialismo.

\begin{abstract}
Esse processo ajuda-nos a entender porque o colonialismo não é somente um período do nosso passado histórico, mas também uma característica necessária do capitalismo em sua dinâmica de acumulação incessante de capital que implica, inclusive, expansão geográfica para regiões tradicionalmente ocupadas por outros grupos-classes sociaisetnias-povos-nacionalidades. Esses grupos diferentes por suas características étnicoraciais são inferiorizados por ideologias que os tratam como "atrasados", "subdesenvolvidos", "pobres" e, deste modo, não se os vê pelas qualidades que lhes são próprias e são tratados com o peso da colonialidade que ainda nos atravessa. Afinal, não se coloniza quem é igual, daí a necessidade de justificar a expansão modernizante-desenvolvimentista do capital inferiorizando previamente o outro, o diferente. Enfim, os grupos-classes sociais-etnias-povos-nacionalidades outros continuam sendo tratados como o eram no período colonial, mesmo depois da independência formal do nosso país. Como bem afirmou o sociólogo peruano Aníbal Quijano para a América Latina: “o fim do colonialismo não significou o fim da colonialidade" (...). Observemos que o que normalmente se chama modernização das regiões para onde o capital se expande é, nada mais nada menos, que sua colonização. Daí falarmos de padrão de acumulação de capital moderno-colonial ${ }^{10}$.
\end{abstract}

Nesse cenário, embora o processo de dominação socioeconômica em face da América Latina estivesse em pleno desenvolvimento, a Convenção sobre Diversidade Biológica ${ }^{11}$ surge como alternativa para resguardar a biodiversidade latino-americana, busca-se evitar a exploração desenfreada existente dos recursos naturais existentes na região.

Em contraposição, o Acordo TRIPs ${ }^{12}$ vem contrapor as regras estabelecidas pela Convenção sobre Diversidade Biológica, limitando sua aplicabilidade através do estabelecimento de diversos mecanismos que aliam propriedade intelectual à exploração comercial:

Aplicados aos produtos ou processos biotecnológicos, os direitos de propriedade intelectual destinam-se a garantir uma titularidade individual exclusiva de auferir os benefícios gerados na exploração comercial e econômica desses produtos ou processos apropriados. Os Estados, contudo, não se encontram em condições equânimes de produção biotecnológica, o que resulta na segmentação entre os países desenvolvidos, cuja tecnologia os coloca na condição de inventores, e os

\footnotetext{
http://biblioteca.clacso.edu.ar/clacso/becas/20131013100118/Quental trabalho_final.pdf - Acesso em 22 de novembro de 2015 - p. 06).

${ }^{10}$ PORTO-GONÇALVES, Carlos Walter. CUIN, Danilo Pereira. Geografia dos conflitos por terra no Brasil (2013): Expropriação, Violência e R- Existência. 2014, p. 24.

11 ORGANIZAÇÃ̃O DAS NAÇÕES UNIDAS. Declaração do Rio sobre Meio Ambiente e Desenvolvimento. Disponível em: 〈http://www.onu.org.br/rio20/img/2012/01/rio92.pdf > - Acesso em 06 de janeiro de 2016.

${ }_{12}$ BRASIL, Decreto n ${ }^{\circ}$. 1355/1994. Disponível em: http://www.inpi.gov.br/legislacao-1/27-trips-portugues1.pdf Acesso em 20 de setembro de 2016.
} 
países em desenvolvimento e os menos desenvolvidos, que são pobres em capacidade tecnológicas, mas ricos em recursos naturais utilizados como matéria-prima pelas corporações da biotecnologia ${ }^{13}$.

Obviamente, não se pode negar que as contribuições advindas do Direito Internacional como um todo e, principalmente, dos ditames positivados na Convenção sobre Diversidade Biológica, a fim de conter a degradação em massa do meio ambiente, foram indispensáveis para o despertar da sociedade global, bem como para a modificação positiva inerente à relação homem - natureza. No entanto, acredita-se que as regras que emanam do capital e regem a globalização ou globalitarismo ${ }^{14}$, nos dizeres de Milton Santos, podem superar em termos práticos as tentativas de conter a utilização sem fronteiras da biosfera.

Ademais, as adversidades consubstanciadas no caráter inconstante do Direito Internacional Ambiental são fortemente motivadas pela diversidade de interesses estatais que acabam por dificultar a formação e a aplicabilidade dos instrumentos internacionais relativos à proteção ambiental. Isso se deve sumariamente pelo fato de que, o regramento ambiental na ordem internacional foi criado visando outros fins que não garantir a proteção da biodiversidade de forma específica. Nesse diapasão, Fernando Estenssoro Saavedra nos mostra que os debates ambientais surgiram como um jargão estratégico para coibir o levante de outras bandeiras políticas que não aquelas defendidas pelas elites norte-americanas:

Desde uma perspectiva histórica, o debate ambiental na política mundial surgiu após o fim da Segunda Guerra Mundial, como uma temática de interesse geopolítico e estratégico para as elites intelectuais, políticas e econômicas norte-americanas. Interesse esse que rapidamente foi compartilhado por seus aliados europeus ocidentais. É um debate que, originado em torno da ideia de crise ambiental global, será uma expressão dos diferentes argumentos e alternativas possíveis de avaliar, por parte dos Estados Unidos e seus aliados, para evitar o avanço do comunismo em âmbito mundial e contê-lo dentro das fronteiras e áreas de influência soviética que foi negociada em Yalta e Potsdam.

Sobre isso, a temática da crise ambiental, em primeiro lugar surgiu em meio a um debate maior que significava a política de contenção do comunismo na nascente

\footnotetext{
${ }^{13}$ VIEIRA, Vinicius Garcia. Direito da biodiversidade e América Latina: a questão da propriedade intelectual. Ijuí: Unijuí, 2012, p. 94-95.

${ }^{14}$ A fim de identificar o globalitarismo enquanto o conjunto de diversas formas totalitárias de imposição ideológica e de dominação em favor do capital, Milton Santos disciplina que o globalitarismo: "São, todas essas, condições para a difusão de um pensamento e de uma prática totalitárias. Esses totalitarismos se dão na esfera do trabalho como, por exemplo, num mundo agrícola modernizado onde os atores subalternizados convivem, como num exército, submetidos a uma disciplina militar. O totalitarismo não é, porém, limitado à esfera do trabalho, escorrendo para a esfera política e das relações interpessoais e invadindo o próprio mundo da pesquisa e do ensino universitários, mediante um cerco às idéias cada vez menos dissimulado. Cabe-nos, mesmo, indagar diante dessas novas realidades sobre a pertinência da presente utilização de concepções já ultrapassadas de democracia, opinião pública, cidadania, conceitos que necessitam urgente revisão, sobretudo nos lugares onde essas categorias nunca foram claramente definidas nem totalmente exercitadas" (SANTOS, Milton. Por uma outra globalização: do pensamento único à consciência universal. Rio de Janeiro: Record, 2001, p. 27).
} 
guerra fria e, em segundo lugar, foi um argumento alternativo ou um contraargumento à crença dominante das elites políticas de que o avanço do comunismo no Terceiro Mundo em geral e na América Latina em particular, podia ser freado mediante a elevação do nível de vida de seu povo faminto, apoiando-os para alcançar o status de países desenvolvidos mediante um processo de modernização e industrialização crescente ${ }^{15}$.

Nesse ponto é reforçada a ideia de um processo de colonialidade, referida anteriormente, onde referências ideológicas, políticas e econômicas são impostas pelo poder hegemônico do Norte, sob o manto ideológico do desenvolvimento sustentável e de contenção da crise ambiental global: desencadeando em ações em âmbito internacional, além da edição de tratados e convenções que não se legitimam, visto que os fins a que se prestam corroboram fatores que privilegiam o empobrecimento dos países antes colonizados, e por consequência o crescimento da desigualdade entre Norte e $\mathrm{Sul}^{16}$.

O que se vislumbra na contemporaneidade é a utilização dos inúmeros mecanismos tecnológicos que estão sendo desenvolvidos em favor da sedimentação dessa nova colonização: consistente agora, na dominação hegemônica pautada na mercadorização da biodiversidade, reduzindo-a aos recursos genéticos enquanto objeto da ciência com substâncias e informações comercializáveis e submissão dos povos e saberes do Sul aos ditames da ciência e da biotecnologia.

Diante desse contexto, surgem propostas que visam congregar esforços visando o surgimento de alternativas para defesa dos conhecimentos tradicionais e do patrimônio genético pertencente à América Latina, frente aos desmandos dos países desenvolvidos.

\footnotetext{
${ }^{15}$ SAAVEDRA, Fernando Estenssoro. História do debate ambiental na política mundial 1945-1992. Trad. Daniel Rubens Cenci. Ijuí: Unijui, 2014, p. 211.

${ }^{16}$ É hoje evidente que, para além das dimensões econômicas e políticas, o colonialismo teve uma forte dimensão epistemológica e que, em parte por isso, não terminou com o fim dos imeríos coloniais. Por isso, importa avaliar o modo como o Sul foi e continua a ser afectado por este processo de colonização, sem o que não será possível pensar a diversidde epistemológica do mundo. Muitos dos estudos que integram este volume ilustram de modo inequívoco que o fim do colonialismo político não significou o fim do colonialismo com relação social, o que, segundo Quijano, designamos por colonialidade do poder e do saber (Quijano, 2000; Lander, 2000). Neste contexto, as reflexões de Aimé Césaire sobre a história da violência e da incompreensão produzidas pelo capitalismo permanecem actuais no contexto do debate sobre a relação entre conhecimento e poder:

Falam-me de progresso, de "realizações, de doenças curadas, de níveis de vida elevados acima de si próprios. Eu, eu falo de sociedades esvaziadas de si próprias, de culturas espezinhadas, de instituições minadas, de terras confiscadas de religiões assassinadas, de magnificências artísticas aniquiladas, de extraordinárias possibilidades suprimidas. Lançam-se à cara factos, estatísticas, quilometragens de estradas, canais, de caminho de ferro. Mas eu falo de milhares de homens sacrificados no Congo-Oceando. (...) Falo de milhões de homens arrancados aos seus deuses, à sua terra, aos seus hábitos, à sua vida, à dança, à sabedoria. Falo de milhões de homens a quem inculcaram sabiamente o medo, o complexo de inferioridade, o tremor, a genuflexão, o desespero, o servilismo (...) (SANTOS, Boaventura de Sousa. Semear outras soluções: os caminhos da biodiversidade e dos conhecimento rivais. Org. Rio de Janeiro: Civilização Brasileira, 2005).
} 
Dentre tais propostas, a criação de um regime sui generis para a proteção dos conhecimentos tradicionais e do patrimônio genético revela-se como uma dos mais repercutidos no cenário latino-americano da atualidade, havendo no entanto, inúmeras críticas que evidenciam a possível ineficácia quanto a criação de mais um instrumento normativo, frente a existência de outros instrumentos que já tratam da questão, como a própria Convenção sobre Diversidade Biológica.

Assim, levando em consideração as proposições efetuadas por Juliana Santilli e Vinicius Garcia Vieira, quanto à criação de um regime sui generis para a proteção dos conhecimentos tradicionais e do patrimônio genético latino-americano, pretende-se evidenciar as fragilidades de ambas as proposições, bem como suas potencialidades, para então verificarse em que moldes se garantia a eficácia de um regime sui generis latino-americano.

\section{2 - NOVOS PARÂMETROS PARA O EMPODERAMENTO LATINO-AMERICANO: LIMITES E POSSIBILIDADES PARA A CONSTRUÇÃO DE UM REGIME SUI GENERIS}

Ao vislumbrar-se os contrapontos existentes na realidade posta, no que concerne à questão do patrimônio genético e dos conhecimentos tradicionais sob a perspectiva da nova colonialidade latino-americana, direciona-se o pensamento para a possibilidade de se introduzir novos mecanismos capazes de conter a exploração desordenada: tanto no que diz respeito ao patrimônio genético, como no que tange aos conhecimentos tradicionais. Sob tais paradigmas, o advento de um regime sui generis de proteção estaria entre os mecanismos eficazes para combater a desordem do sistema, sendo esta proposta de Juliana Santilli e Vinicius Garcia Vieira, ainda que sob prismas diferenciados.

Santilli, ao tratar dos conhecimentos tradicionais associados à biodiversidade, assevera que esses conhecimentos tradicionais, são produzidos e gerados de forma coletiva, a partir de ampla troca e circulação de ideias e informações, e transmitidos oralmente, de uma geração à outra ${ }^{17}$. Nesse ínterim, a imposição da cientifização do conhecimento mostra-se como estratégia do sistema capitalista para a apropriação indevida de conhecimentos tradicionais associados ao patrimônio genético, de forma que o instituto da propriedade intelectual surge como mecanismo

\footnotetext{
${ }^{17}$ SANTILLI, Juliana. Conhecimentos tradicionais Associados à biodiversidade: elementos para a construção de um regime jurídico sui generis de proteção. PLATIAU, Ana Flávia Barros, VARELLA, Marcelo Dias (org.). Diversidade biológica e conhecimentos tradicionais. Belo Horizonte: Del Rey, 2004.
} 
legitimador da apropriação dos saberes tradicionais em favor das grandes corporações ligadas a biotecnologia.

Vandana Shiva, ao tratar da mercadorização dos conhecimentos tradicionais associados ao patrimônio genético, revela mecanismos para a validação do processo de apropriação indevida, de modo a ser considerado universalmente em prol dos imperativos econômicos globais:

\begin{abstract}
A fronteira da criação faz com o conhecimento o que a fronteira da produção faz com o trabalho: ela exclui as contribuições criativas das mulheres assim como também dos camponeses e povos tribais do Terceiro Mundo e os vê como envolvidos em processos biológicos repetitivos e não pensantes. Separar produção de reprodução, caracterizar a primeira como econômica e a segunda como biológica são alguns dos pressupostos subjacentes tratados como naturais, mesmo que tenham sido construídos social e politicamente ${ }^{18}$.
\end{abstract}

Nesse contexto, os principais elementos para construção de um regime sui generis no ordenamento brasileiro, para proteção aos conhecimentos tradicionais associados à biodiversidade, parte dos componentes tangíveis ou materiais (como territórios e recursos naturais) e intangíveis (como conhecimentos, inovações e práticas) da biodiversidade, ligados ao reconhecimento e a proteção aos conhecimentos tradicionais de um sistema jurídico que efetivamente proteja os direitos territoriais e culturais desses povos e populações tradicionais ${ }^{19}$. A autora destaca ainda a necessidade de proteção da integridade intelectual e cultural, bem como dos valores espirituais associados aos conhecimentos tradicionais e o reconhecimento de seu valor intrínseco, assim como a consideração de que a simples transformação dos conhecimentos tradicionais em mercadorias ou commodities, obedece a lógica do contexto econômico, social e cultural, que escapam ao controle de um instrumento jurídico, salientando que "ao pretender criar um regime sui generis de proteção aos conhecimentos tradicionais associados à biodiversidade, o Direito elaborado pelo Estado brasileiro deve avançar no reconhecimento da juridicidade do direito costumeiro, não-oficial, dos povos indígenas, quilombolas e populações tradicionais" 20.

Santilli assevera que nesse processo de construção de tal regime devem ser observados conhecimentos já produzidos pelas ciências sociais e etnociências sobre as características

\footnotetext{
${ }^{18}$ SHIVA, Vandana. Biopirataria: a pilhagem da natureza e do conhecimento. Petrópolis: Vozes, 2001.

${ }^{19}$ SANTILLI, Juliana. Conhecimentos tradicionais Associados à biodiversidade: elementos para a construção de um regime jurídico sui generis de proteção. PLATIAU, Ana Flávia Barros, VARELLA, Marcelo Dias (org.). Diversidade biológica e conhecimentos tradicionais. Belo Horizonte: Del Rey, 2004, p. 355.

${ }^{20}$ SANTILLI, Juliana. Socioambientalismo e novos direitos: proteção jurídica à diversidade biológica e cultural. São Paulo: Peirópolis, 2005, p. 156.
} 
intrínsecas dos processos criativos dos povos tradicionais, levando-se em consideração, alguns elementos fundamentais como: o reconhecimento e fortalecimento das normas internas do direito costumeiro, não - oficial, dos povos indígenas, quilombolas e populações tradicionais (pluralismo jurídico). Ademais, a autora destaca a necessidade de garantia da titularidade coletiva de direitos intelectuais associados aos conhecimentos tradicionais; livre intercâmbio e troca de informações entre as próprias comunidades tradicionais; distinção entre direitos intelectuais coletivos de conteúdo moral e patrimonial; e o papel do Estado brasileiro, como garantidor do respeito à autonomia de vontade dos povos tradicionais e a requisitos essenciais de validade de atos jurídicos ${ }^{21}$.

\begin{abstract}
A criação de um regime jurídico verdadeiramente sui generis e apropriado para a proteção dos conhecimentos tradicionais associados deve se basear nas concepções do pluralismo jurídico, e no reconhecimento da diversidade jurídica existente nas sociedades tradicionais, expressão da sua diversidade cultural. É necessário realizar aquilo que Benatti denomina de "esforço teórico interdisciplinar comprometido com os avanços dos diversos saberes das ciências humanas", ou seja, socorrer-se dos conhecimentos produzidos por outras áreas e saberes científicos para construir, juridicamente, um regime de proteção que atenda às peculiaridades e especificidades dos conhecimentos tradicionais ${ }^{22}$.
\end{abstract}

Com objetivos semelhantes, mas propondo métodos distintos, Vinícius Garcia Vieira propõe um regime sui generis baseado em uma articulação regional que seja capaz de levar em conta as peculiaridades próprias das comunidades tradicionais: tendo em vista que as digressões pertinentes aos processos biotecnológicos não podem ser consideradas unicamente no tratamento do patrimônio genético e dos conhecimentos tradicionais, condição que reflete o empoderamento dos povos tradicionais.

Neste sentido, o regime sui generis latino-americano seria um mecanismo de legitimação das diversas formas de conhecimento, não se restringindo tão somente ao conhecimento científico moderno.

Na análise das distinções entre Sul e Norte, foi identificado que a América Latina tem
seu espaço caracterizado como sociobiodiverso, o que implica em assumir a
responsabilidade em desempenhar o papel principal na condução das negociações
internacionais para a proteção dos conhecimentos dos povos indígenas e comunidades
tradicionais acerca da diversidade da fauna e da flora que compõem o espaço regional
historicamente habitado por estes povos autóctones. Então, um regime regional sui
generis de proteção da biodiversidade deve ser estruturado a partir de uma declaração

${ }^{21}$ SANTILLI, Juliana. Conhecimentos tradicionais Associados à biodiversidade: elementos para a construção de um regime jurídico sui generis de proteção. PLATIAU, Ana Flávia Barros, VARELLA, Marcelo Dias (org.). Diversidade biológica e conhecimentos tradicionais. Belo Horizonte: Del Rey, 2004, p. 357-365.

22 SANTILLI, Juliana. Socioambientalismo e novos direitos: proteção jurídica à diversidade biológica e cultural. São Paulo: Petrópolis, 2005, p. 152. 
de direitos dos povos tradicionais, com a estipulação de mecanismos assecuratórios das formas costumeiras de pertencimento comunitário desses direitos ao acervo cultural, social, identitário e econômico desses povos, cuja organização comunitária é responsável pela manutenção da biodiversidade ${ }^{23}$.

Sob essa perspectiva, o autor coloca o modelo apresentado como um regime regional para a construção de uma alternativa de proteção da biodiversidade no continente latinoamericano, além de representar um meio contra-hegemônico em relação às estratégias da colonialidade então vigentes ${ }^{24}$.

Segundo o autor, um marco regional que venha a reconhecer a diversidade social do continente, assim como as diversas percepções culturais da relação homem - natureza, seria fundamental para um processo de integração vinculado à biodiversidade existente no território latino-americano.

Ambas as proposições colocam em primeiro plano a valorização das comunidades tradicionais e seu empoderamento, todavia Santilli retrata sua proposta no cenário nacional sem colocar de maneira específica a forma legal em que esse regime sui generis se perfectibilizaria, enquanto Vieira dispõe acerca de um instrumento internacional de âmbito regional.

Levando em conta que as necessidades e peculiaridades ultrapassam as fronteiras nacionais no que tange à exploração do patrimônio genético e dos conhecimentos tradicionais, tem-se que a proposta de um instrumento internacional de âmbito regional que tenha por base o reconhecimento da identidade latino-americana, sua valorização, assim como a valorização de novos parâmetros na relação homem-natureza engendraria parâmetros contra-hegemônicos.

A questão, no entanto, é que a construção de um instrumento regional de tal relevância pressupõe em larga medida seu caráter coercitivo enquanto condição para sua efetividade, além da participação dos diversos setores da sociedade latino-americana para sua construção.

Nesse sentido, pode-se utilizar como parâmetros para a construção de um regime sui generis nesses moldes a Declaração sobre o Princípio 10 na América Latina e no Caribe, a qual manifestou o compromisso dos países idealizadores (Chile, Costa Rica, Equador, Jamaica,

\footnotetext{
${ }^{23}$ VIEIRA, Vinicius Garcia. Direito da biodiversidade e América Latina: a questão da propriedade intelectual. Ijuí: Unijuí, 2012, p. 152.

${ }^{24}$ Nessa perspectiva, o sistema regional sui generis deve articular elementos para reequilibrar as relações de poder inerentes ao regime internacional de patentes, ao modelo Trips da OMC, que estabelece normas jurídicas cujos conteúdos permitem a individualização de direitos de propriedade intelectual a empresas de biotecnologias ou pesquisadores dessas empresas. Significa que a ordem jurídica do Trips, inicialmente pensada para uma sociedade uniforme, urbana, industrial e composta apenas por um modo existencial dominado pela percepção econômica, deve ser transformada para amparar a pluralidade da existência humana, incluindo as comunidades tradicionais, constituídas por valores, cultos, tradições, formas de conhecimento e noções de propriedade, elementos esses distintos daquela sociedade uniforme idealizada (VIEIRA, 2012, p. 156).
} 
México, Panamá, Paraguai, Peru, República Dominicana e Uruguai) de implementarem um plano de ação cuja vigência seria entre os anos de 2012 e 2014, com o apoio da Comissão Econômica para a América Latina e o Caribe - CEPAL, visando efetuar as ações necessárias para a implantação de um instrumento regional garantidor da aplicabilidade do Princípio 10 nos Estados contratantes.

A partir da superveniência da Declaração sobre o Princípio 10 na América Latina e no Caribe, o aprofundamento de estudos quanto as ações que deveriam ser consideradas para a elaboração de um instrumento regional comum, inicia a partir da elaboração de um roteirovisando iniciar un proceso destinado a fortalecer el diálogo y la cooperación regional y contar con un instrumento regional en matéria de derechos de acceso a la información, participación y justicia ambientales ${ }^{25}$.

Por conseguinte, em conformidade com o roteiro antes elaborado, houve a confecção de um Plano de Ação que passou a estabelecer tarefas a serem executadas por grupos de trabalhos distintos, os quais possuíam o objetivo de congregar elementos para a posterior elaboração do instrumento regional para implementação do Princípio 10 no plano prático até o ano de 2014, cuja coordenação ficou a cargo da Comissão Econômica para a América Latina e o Caribe - CEPAL com a promoção de modalidades de participação do público interessado.

A partir daí, diversas foram as contribuições advindas da sociedade civil, representadas por instituições de ensino superior, associações, fundações, $O N G$ 's e cidadãos. De 05 à 07 de maio de 2015, realiza-se então a Primera Reunión del Comité de Negociación del Acuerdo Regional sobre el Acceso a la Información, la Participación Pública y el Acceso a la Justicia en Asuntos Ambientales en América Latina y el Caribe, apresentando-se nessa oportunidade o Documento Preliminar del Instrumento Regional sobre el Acceso a la Información, la Participación Pública y el Acceso a la Justicia en Asuntos Ambientales en América Latina y el Caribe.

Apesar deste instrumento regional não ter logrado êxito no que concerne a inexistência de coercitividade por parte de suas disposições aos países signatários, é capaz de demonstrar

\footnotetext{
${ }^{25}$ COMISSÃO ECONÔMICA PARA A AMÉRICA LATINA E O CARIBE - CEPAL. Propuesta de naturaleza y contenidos a desarrollar en el instrumento regional para consideración en la Cuarta Reunión de los Puntos Focales designados por los gobiernos de los países signatarios de la Declaración sobre la Aplicación del Principio 10 de la Declaración de Río sobre el Medio Ambiente y el Desarrollo en América Latina y el caribe. Disponível em: $\langle$ http://www.cepal.org/dmaah/noticias/noticias/9/54369/Propuesta de naturaleza_y_contenidos.pdf $>$ - Acesso em 06 de janeiro de 2016.
} 
que é possível uma outra realidade na América Latina quanto ao ponto crucial que sustenta o processo de colonialidade.

Assim como a congregação de esforços para a concretização do Princípio 10 foi e é possível, a construção de um regime sui generis por meio de um instrumento regional mostrase possível, ainda que os esforços devam ser de grande monta e que novas perspectivas quanto a relação homem-natureza sejam internalizadas pelos povos latino-americanos, a fim de garantir efetividade plena à tais ideais do porvir.

\section{CONCLUSÃO}

Os argumentos delineados são capazes de demonstrar que a emergência contemporânea quanto à dependência imposta à América Latina, baseia-se sumariamente em questões relacionadas à exploração do patrimônio genético e dos conhecimentos tradicionais do continente: fomento para o desenvolvimento econômico desejado pelos países de Primeiro Mundo. Nesse diapasão, a existência do processo de colonialidade configura-se não só pela exploração e apropriação dos recursos já citados, mas também pela subversão da Convenção sobre Diversidade Biológica, que então passa a legitimar interesses econômicos sob os auspícios do Acordo Trips.

A breve explanação acerca das legislações internacionais que tratam acerca do tema, demonstra que tais textos normativos por si só não são suficientes para a proteção do patrimônio genético e dos conhecimentos tradicionais associados na América Latina, tendo em vista que textos legais são imbuídos de permissividades nas quais se sobressai a deixa de conceder a grupos hegemônicos possibilidades de ações que permitem o alcance de seus interesses economicistas. Sob esse aspecto, vislumbra-se que a cientifização e a tecnização do conhecimento pressupõem a unicidade do saber, tornando válidas somente as perspectivas eurocêntricas que obedecem o modelo cientifico e técnico imposto.

Frente a desconsideração dos saberes tradicionais e a apropriação indevida em prol das grandes corporações ligadas à biotecnologia, apresentou-se então as propostas de Juliana Santilli e Vinicius Garcia Vieira como modo de contrapor a ordem posta, em defesa da identidade e peculiaridades dos povos latino-americanos. Todavia, sabe-se que a eficácia de um regime sui generis está condicionada a coercitividade no cumprimento de um possível instrumento regional e, a inexistência de influências econômicas que possam influenciar a construção da norma ou sua interpretação em favor do capital. 
Diante do exposto, visando sanar a problemática que induziu a presente pesquisa, temse que a construção de um regime sui generis, tomando por base as lições dos autores citado acima, mostra-se como meio capaz de subverter a ordem posta mediante a construção de um instrumento regional com força coercitiva, tomando como exemplo o processo de confecção de um instrumento regional para efetivação do Princípio 10 na América Latina, o qual embora não tenha força coercitiva demonstra a possibilidade de uma reconfiguração nos parâmetros latinoamericanos quanto a relação homem-natureza.

\section{REFERÊNCIAS}

ASSIS, Wendell Ficher Teixeira. Do colonialismo à colonialidade: expropriação territorial na periferia do capitalismo. In: Caderno CRH, v. 27, n. 72. Salvador: set-dez. 2014. Disponível em: http://www.scielo.br/pdf/ccrh/v27n72/11.pdf -Acesso em 15 de setembro de 2016.

BRASIL, Decreto no. 1355/1994. Disponível em: http://www.inpi.gov.br/legislacao-1/27trips-portugues1.pdf - Acesso em 20 de setembro de 2016.

BRUZZONE, Elsa. Las guerras del água: América del Sur, en la mira de las grandes potencias. $1^{\text {a }}$ Ed. Buenos Aires: Capital Intelectual, 2009.

COMISSÃO ECONÔMICA PARA A AMÉRICA LATINA E O CARIBE - CEPAL. Propuesta de naturaleza y contenidos a desarrollar en el instrumento regional para consideración en la Cuarta Reunión de los Puntos Focales designados por los gobiernos de los países signatarios de la Declaración sobre la Aplicación del Principio 10 de la Declaración de Río sobre el Medio Ambiente y el Desarrollo en América Latina y el caribe. Disponível em: $<$ http://www.cepal.org/dmaah/noticias/noticias/9/54369/Propuesta_de_naturaleza_y_contenidos.p df $>$ - Acesso em 06 de janeiro de 2016.

ORGANIZAÇÃO DAS NAÇÕES UNIDAS. Declaração do Rio sobre Meio Ambiente e Desenvolvimento. Disponível em: 〈http://www.onu.org.br/rio20/img/2012/01/rio92.pdf > Acesso em 06 de janeiro de 2016.

PORTO-GONÇALVES, Carlos Walter. CUIN, Danilo Pereira. Geografia dos conflitos por terra no Brasil (2013): Expropriação, Violência e R- Existência. 2014. 
QUENTAL, Pedro de Araujo. Dilemas da integração regional na América do Sul: a lógica territorial da IIRSA e suas implicações socioespaciais. Conselho Latino-americano de Ciências Sociais. Disponível

em: http://biblioteca.clacso.edu.ar/clacso/becas/20131013100118/Quental trabalho final.pdf - Acesso em 22 de novembro de 2015.

QUIJANO, Aníbal. Colonialidade do poder, eurocentrismo e América Latina. Consejo Latinoamericano de Ciencias Sociales. Buenos Aires, CLACSO: 2005.

SAAVEDRA, Fernando Estenssoro. História do debate ambiental na política mundial 1945-1992. Trad. Daniel Rubens Cenci. Ijuí: Unijui, 2014

SANTILLI, Juliana. Conhecimentos tradicionais Associados à biodiversidade: elementos para a construção de um regime jurídico sui generis de proteção. PLATIAU, Ana Flávia Barros, VARELLA, Marcelo Dias (org.). Diversidade biológica e conhecimentos tradicionais. Belo Horizonte: Del Rey, 2004.

Socioambientalismo e novos direitos: proteção jurídica à diversidade biológica e cultural. São Paulo: Peirópolis, 2005.

Santos, Boaventura de Sousa., Introducción: las epistemologías del Sur in CIDOB (org.), Formas-Otras. Saber, nombrar, narrar, hacer. Barcelona: CIDOB Ediciones, 2011

SANTOS, Boaventura de Sousa. Semear outras soluções: os caminhos da biodiversidade e dos conhecimento rivais. Org. Rio de Janeiro: Civilização Brasileira, 2005.

SANTOS, Milton. Por uma outra globalização: do pensamento único à consciência universal. Rio de Janeiro: Record, 2001.

SHIVA, Vandana. Biopirataria: a pilhagem da natureza e do conhecimento. Petrópolis: Vozes, 2001.

VIEIRA, Vinicius Garcia. Direito da biodiversidade e América Latina: a questão da propriedade intelectual. Ijuí: Unijuí, 2012. 